\title{
Factors Predicting Adherence to Lifestyle Modification among Patients with Coronary Artery Disease
}

\author{
Zamzaliza Abdul Mulud, Nor Masita Esa
}

Centre of Nursing Studies, Faculty Health Sciences, Universiti Teknologi MARA, Puncak Alam, Selangor, Malaysia

zamzaliza@uitm.edu.my, masita.esa153@gmail.com Tel: +60332584305

\begin{abstract}
Lifestyle modification is essential to improve quality of life among patients with coronary artery disease. However, it is one of the challenges for patients with coronary artery disease. The aim of the study to assess the adherence level and factors affecting lifestyle modifications. A cross-sectional study among 113 patients was conducted using a self-administered questionnaire. The findings of the study indicated that the level of adherence to lifestyle

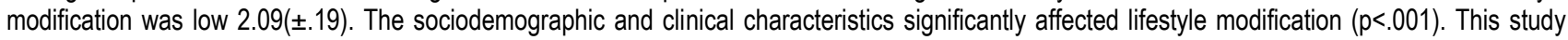
found factors affecting lifestyle modification that essential to initiate development interventions to improve quality of life.
\end{abstract}

Keywords: Lifestyle modification; adherence; quality of life; coronary artery disease

eISSN: 2398-4287@ 2020. The Authors. Published for AMER ABRA cE-Bs by e-International Publishing House, Ltd., UK. This is an open access article under the CC BYNC-ND license (http://creativecommons.org/licenses/by-nc-nd/4.0). Peer-review under responsibility of AMER (Association of Malaysian Environment-Behaviour Researchers), ABRA (Association of Behavioural Researchers on Asians) and cE-Bs (Centre for Environment-Behaviour Studies), Faculty of Architecture, Planning \& Surveying, Universiti Teknologi MARA, Malaysia.

DOI: https://doi.org/10.21834/ebpj.v5i14.2222

\subsection{Introduction}

Coronary artery disease (CAD) is a serious condition which the plaque build up in the coronary artery that limits the blood supply to the heart muscle. Coronary artery disease ranging from Unstable Angina (UA), Non-ST Elevation Myocardial Infarction (NSTEM) to STElevation Myocardial Infarction depending upon degree and acuteness of coronary occlusion by the plaque. One of the leading causes of death worldwide and account for large numbers of hospitalization is coronary artery disease as the numbers are increasing yearly (WHO, 2014). Non-communicable diseases (NCDs) are the leading cause of death in Malaysia, mainly due to cardiovascular disease and the most significant contributors in terms of disability among Malaysians (Ministry of Health Malaysia, 2016).

Adherence to lifestyle modification and medication is the most important secondary prevention to reduce the risk of complications among patients with CAD such as death, congestive cardiac failure (CCF) and recurrent admission. A study found that the risk of recurrent cardiovascular events substantially negatively associated with adherence to behaviours advice included diet, exercise and smoking cessation (Chow et al., 2010). Adherence to lifestyle modification is one of the most significant challenges of secondary prevention among patients with CAD. A study finding demonstrated the difficulty of modifying the lifestyle habits among 130 patients after six months of an acute cardiovascular event (Sofi et al., 2011). It is shown that adherence to lifestyle modification is a crucial issue among patient with CAD.

Therefore, this study will identify factors affecting adherence to lifestyle modification among patients with CAD (is it affected by sociodemographic characteristics and clinical data such as smoking status and cardiovascular risk factors. This study conducted based on two objectives, which are to examine the adherence level to lifestyle modification and identify the factors affecting the adherence level to lifestyle modification among patients with CAD.

eISSN: 2398-4287C 2020. The Authors. Published for AMER ABRA cE-Bs by e-International Publishing House, Ltd., UK. This is an open access article under the CC BYNC-ND license (http://creativecommons.org/licenses/by-nc-nd/4.0/). Peer-review under responsibility of AMER (Association of Malaysian Environment-Behaviour Researchers), ABRA (Association of Behavioural Researchers on Asians) and cE-Bs (Centre for Environment-Behaviour Studies), Faculty of Architecture, Planning \& Surveying, Universiti Teknologi MARA, Malaysia.

DOI: https://doi.org/10.21834/ebpj.v5i14.2222 


\subsection{Literature Review}

\subsection{Adherence to lifestyle modification}

Lifestyle modification also referred to as behavioural disease prevention, includes five primary components: diet, exercise, smoking cessation, stress management and medical therapy(Alm-Roijer, Stagmo, Udén, \& Erhardt, 2004). Patients who adhere to a diet, exercise, smoking cessation, weight reduction and medical treatment recommendations by the cardiologist or healthcare providers explained the adherence to the lifestyle modification(Tibebu, Mengistu, \& Negesa, 2017). Previous literature has demonstrated that lifestyle modification and cardiac rehabilitation can optimize risk factors for patients with cardiovascular disease (Aldana et al., 2003; lestra, 2005). However, one of the most significant challenges in secondary prevention among patients with CAD was adherence to lifestyle modifications.

\subsection{Factors related to adherence level}

The sociodemographic aspect where is significant to the patients' background is one of the factors that related to the adherence level. These are included patients' background such as age, gender, marital status, education background, and monthly income. Other than that, co-morbidities risk factors such as Diabetes Mellitus (DM), Hypertension and family background of cardiac disease also the significant related to the adherence level among the patients.

Female respondents compared to male were found to be twice more likely to adhere to the recommended lifestyle modifications reported by Tibebu, Mengistu, \& Negesa, (2017). This study also reported that respondents in the old aged adult group were found to be six times more adherent than respondents in the young adult age group. This finding contrast with a study conducted by Zeleke Negera \& Charles Epiphanio, (2020) were found female gender, age $>60$ years, diabetes duration of $>5$ years and lack of social support to be independent predictors of nonadherence to physical activity recommendations.

Meanwhile, adherence to dietary recommendations was higher in males than females in a study among 385 patients with Diabetes Mellitus (DM) in Nepal, India (Parajuli, Saleh, Thapa, \& Ali, 2014). Parajuli et al., (2014) found level adherence to dietary recommendations decreased with increasing age. The several previous studies that investigated the adherence level to lifestyle modification among patients with CAD-related to some of the sociodemographic data and cardiovascular risk factors.

\subsection{Methodology}

\subsection{Study Design and Population}

A cross-sectional study was conducted among 113 CAD patients in Hospital Serdang, from 1 August to 31 December 2019. Hospital Serdang is one of the heart centres under the Ministry of Health that is located in Klang Valley. The study population was patients admitted to the cardiology department diagnosed with Unstable Angina (UA), Non-ST Elevation Myocardial Infarction (NSTEM) to STElevation Myocardial Infarction.

Patients aged above 21-year-old and presented with CAD event, defined and supported by electrocardiogram and cardiac enzyme blood test. Patients with chronic disease condition (i.g., cancer, Acquired Immune Deficiency Syndrome (AIDS) and Hypoxic Ischemic Encephalopathy (HIE)), unstable mental condition (e.g., depression, delirium and Alzheimer disease) excluded from this study. Patients identify with barrier language also excluded from the study.

\subsection{Sample Size and Sampling Technique.}

G*Power 3.0 software was used to calculated the sample size. Using a power level of 0.80 and alpha level of 0.05 and effect size of 0.50 for a two-tailed independence t-test, the estimated sample size was 103 based on previous similar study (Eshah, 2013) that measured adherence to healthy lifestyle. With estimated attrition rate of $10 \%$, the final sample size was 113 patients. The samples of this study were selected using nonprobability, purposive sampling technique. The patients that fulfil the inclusion and exclusion criteria as they fit for the study was recruited.

\subsection{Study Instruments}

Data were collected using the questionnaire. The questionnaire was divided into two sections. Section A namely sociodemographic data, is divided into two categories. The first category which is (a) for sociodemographic items which include sex, age, marital status, race, educational level, work status and monthly income. The other category (b) in section A measures the clinical data from the patients that include smoking status, hypertension, diabetes mellitus, family history of $C A D$, previous cardiac event, treatment for the heart condition, weight and height.

In Section B, the adherence level to lifestyle modification was measured using Health-Promoting Lifestyle Profile II (HPLP-II) developed by Susan, Karen, \& Nola, (1995). HPLP-II, which consists of 52 behaviour statements related to six major components of a healthy lifestyle included health responsibility, physical activity, nutrition, interpersonal relations, spiritual growth and stress management. All items are scored on a 4-point Likert scale (1- Not at all; 2- Sometimes; 3- Often; 4- Always). The score for each item in the six components could range from 1 to 4 . A higher score indicates a greater level of health behaviours. 


\subsection{Data Collection and Measurement}

Data were collected through individual face to face interviewed using a structured questionnaire. The questionnaire was administered by coronary care trained nurse to patients after 72 hours of admitted and prior to discharge. Patients were explained regarding the purposes and objective of this study, and the informed consent was obtained from each patient. The sociodemographic, clinical background and lifestyle modification status were collected via a self-administered questionnaire and assessment with the patients. Each patient took 20 to 30 minutes to completed the questionnaire. The confidentially of the data were assured in the study. The study was approved by Universiti Teknologi Mara (UiTM) Ethics Committee and Medical Research \& Ethics Committee (MREC), Ministry of Health Malaysia (Study ID: NMRR-19-433-45666(IIR).

\subsection{Data Analysis}

Data analysis were performed using IBM Statistical Package SPSS Version 24.0. Sociodemographic data, clinical characteristics analyzed with descriptive analysis were summarized using frequency and percentage. The level of adherence to lifestyle modification related to 6 components of a healthy lifestyle was calculated into means and standard deviations. Multiple linear regression was used to analyses the factors affecting adherence to lifestyle modification among patients.

\subsection{Limitation of the study}

This study population limited for patients with CAD admitted to the Cardiology Department. Hospital Serdang only. The future study suggested to conducting the study in other cardiac centers in Malaysia and a large population area of the patients.

\subsection{Results}

\subsection{Sociodemographic and clinical characteristics of the patients}

A total of 113 patients fulfilled the criteria and participated in the study. The statistics found more than half of the patients was male $(59.3 \%)$ and female $(40.7 \%)$. The mean $( \pm S D)$ age of patients enrolled in the study $51.04( \pm 8.04)$ where $39 \%$ aged below than 50 years old. $49(43.4 \%)$ patients Malay, $36(31.9 \%)$ Chinese, $25(22.1 \%)$ Indian and Other $3(2.7 \%)$. From 113 patients in the study, BMl (Body Mass Index) status for $82(72.6 \%)$ patients was overweight. More than half, 81 (71.7\%) patients have Hypertension, and $69(61.1 \%)$ has dyslipidemia. The sociodemographic and clinical characteristics of the patients enrolled in the study depicted in Table 1.

\begin{tabular}{|c|c|c|c|}
\hline Variables & & Frequency & Percentage $(\%)$ \\
\hline \multirow[t]{2}{*}{ Gender } & Male & 67 & 59.3 \\
\hline & Female & 46 & 40.7 \\
\hline \multirow[t]{5}{*}{ Age } & $21-30$ years & 3 & 2.7 \\
\hline & $31-40$ years & 8 & 7.1 \\
\hline & $41-50$ years & 33 & 29.2 \\
\hline & $51-60$ years & 65 & 57.5 \\
\hline & $61-70$ years & 4 & 3.5 \\
\hline \multirow[t]{4}{*}{ Race } & Malay & 49 & 43.4 \\
\hline & Chinese & 36 & 31.9 \\
\hline & Indian & 25 & 22.1 \\
\hline & Other & 3 & 2.7 \\
\hline \multirow[t]{3}{*}{ Marital Status } & Single & 12 & 10.6 \\
\hline & Married & 95 & 84.1 \\
\hline & Divorced & 6 & 5.3 \\
\hline \multirow[t]{3}{*}{ Education Level } & High School Graduate & 74 & 65.5 \\
\hline & College & 30 & 26.5 \\
\hline & Bachelor's Degree & 9 & 8.0 \\
\hline \multirow[t]{3}{*}{ Monthly Income } & $<3000$ & 66 & 58.4 \\
\hline & $3001-5000$ & 39 & 34.5 \\
\hline & $5001-10000$ & 8 & 7.1 \\
\hline \multirow[t]{3}{*}{ Smoking Status } & Current & 39 & 34.5 \\
\hline & Past & 26 & 23.0 \\
\hline & Never & 48 & 42.5 \\
\hline \multirow[t]{2}{*}{ Hypertension } & Yes & 81 & 71.7 \\
\hline & No & 32 & 28.3 \\
\hline \multirow[t]{2}{*}{ Dyslipidaemia } & Yes & 69 & 61.1 \\
\hline & No & 44 & 38.9 \\
\hline \multirow[t]{2}{*}{ Diabetes Mellitus } & Yes & 39 & 34.5 \\
\hline & No & 74 & 65 \\
\hline \multirow[t]{2}{*}{ Family History } & Yes & 57 & 50.4 \\
\hline & No & 56 & 49.6 \\
\hline \multirow[t]{2}{*}{ Previous Cardiac Event } & Yes & 20 & 17.7 \\
\hline & No & 93 & 82.3 \\
\hline
\end{tabular}




\subsection{Adherence to Lifestyle Modification}

In this study, the level of adherence the patients to practised healthy lifestyle modification as recommended was sometimes with mean $2.09( \pm .19)$. Mean for physical activity $1.78( \pm .37)$ reported that majority of the patients not performed the recommended physical at all, the minimum mean score was 1.00 and the maximum 2.75. Besides, for nutrition, the patients sometimes practised a healthy diet as recommended. The minimum mean score for health responsible was 1.00 (Not at all), and the maximum mean score was 2.78 (Sometimes). It is showed that the patients in this study not accountable for their health with a mean of 1.74( \pm .34$)$. Adherence level to applied recommended stress management was 2.32( \pm .31$)$, which showed 'practised sometimes'. The full summary of a six-items subscale for recommended lifestyle modification described in Table 2.

\subsection{Factors Affecting Adherence to Recommendations for Lifestyle Modification}

Multiple linear regression was performed to identify the factors predicted adherence to lifestyle modification recommendations based on sociodemographic and clinical characteristics. A significant regression equation reported $F(12,100)=6.782$, $p<.001$, with an $R^{2}$, was 449 . Therefore, monthly income $(p<.05)$ and race $(p<001)$ were significant affecting of adherence to lifestyle modifications with (Table.3).

Table 2. Adherence to recommended lifestyle modification ( $N: 113)$

\begin{tabular}{lllll}
\hline & Minimum & Maximum & Mean & Std. Deviation \\
\hline Total HPLP-II & 1.67 & 3.02 & 2.09 & .19 \\
Value of HPLP-II subscale: & & & & \\
$\quad$ Physical Activity & 1.00 & 2.75 & 1.78 & .37 \\
$\quad$ Nutrition & 1.33 & 2.89 & 2.08 & .27 \\
Stress Management & 1.63 & 3.88 & 2.32 & .31 \\
Spiritual Growth & 1.78 & 3.89 & 2.25 & .33 \\
Health Responsibility & 1.00 & 2.78 & 1.74 & .34 \\
Interpersonal Relationship & 1.78 & 3.56 & 2.33 & .28 \\
\hline
\end{tabular}

There were found that independent variables affected adherence to health responsibility in study $F(12,100)=8.284, p<.001$ and $\mathrm{R}^{2}=.499$. On a multiple linear regression model (Table 4), independent variables that affected to adherence to health responsibility for their disease among the patients in the study were age, race both $p<.001$ and marital status $(p<.05)$.

Sociodemographic were found statically significant factors $F(12,100)=12.283, p<.001\left(R^{2}=.596\right)$ that affected adherence to practice physical activity as recommended by the healthcare providers among patients with $C A D$. The significant factors $(p<.05)$ that affected the adherence to practice healthy physical activity among patients with CAD was gender, monthly income and marital status while age $p<.001$ showed in Table 5. In additional, Hypertension was found significantly affected the physical activity among the patients $p<.05$.

Balanced diet intake among patients were reported significantly affected by sociodemographic $F(12,100)=6.642$, $p<.001$ with an $\mathrm{R}^{2}=.444$. The sociodemographic and clinical characteristic $(p<.05)$ that showed affected the balanced diet intake considerably as recommended was monthly income, race, level of education and marital status accessible in Table 6.

Stress management was one of the lifestyle modifications recommended for patients with CAD. The statistic analysis revealed that the sociodemographic affected the patients applied effective stress management in their daily life $(F(12,100)=6.002, p<.001)$ with an $\mathrm{R}^{2}=.419$. Furthermore, Table 7, the independent variables with $\mathrm{p}$-value less than .05 that affected the recommended stress management was age and race $(p<.001)$. Meanwhile, the spiritual growth $F(12,100)=7.980, p<.001$ an $R^{2}=.489$ found affected by race $(p<.001)$, gender and family history of CAD, both were $p<.05$ in Table 8.

The last sub-scale items for lifestyle modification in the study was the interpersonal relationship among patients with CAD. The analysis results showed that $F(12,100)=5.278, p<.001$ explained that the interpersonal relationship affected by sociodemographic data and clinical characteristics. The $p<.001$ for the race and marital status while monthly income was $p<.05$ depicted in Table. 9 .

\subsection{Discussion}

The finding of the study explained that the prevalence of the adherence to lifestyle modification of patients with CAD was low which is reported they're only practising the healthy lifestyle as recommended by healthcare workers 'sometimes'. The higher score for the lifestyle modifications practised in the study was the interpersonal relationship, and the lowest adherence level to lifestyle modification was health responsibility followed by physical activity.

This study identified that gender is one of the factors that affect the adherence to recommended physical activity. This finding was supported by a study that found the nonadherent to physical activity among females were two times than male (Zeleke Negera \& Charles Epiphanio, 2020). In additional marital status also the factors that affect the adherence to physical activity reported in this study. Lack of time among career women and housewife might be the reason related to this finding. Therefore, sociocultural issues in Malaysia which most of the women stay at home most all the time might be explained with this result. Age in this study was found strongly significant factors that affected the physical activity among the patients. Performed routine physical activity could be difficult to older age due to comorbid disease their have and risk of fall and fracture. A study in Bangladesh by Mumu, Saleh, Ara, \& Ali (2015) explained that older age patients (>60years) were related to nonadherence to lifestyle modifications. 
Table 3. Sociodemographic and Clinical Characteristics Affecting Lifestyle Modification (Total HPLP-II)

\begin{tabular}{cllllll}
\hline Dependent Variable & Independent Variables & $\mathrm{B}$ & Std. Error & Beta & $\mathrm{t}$ & P-Value \\
\hline & Age & -.038 & .056 & -.060 & -.675 & .501 \\
& Monthly Income & .162 & .066 & .224 & 2.454 & $.016^{*}$ \\
& Race & -.187 & .031 & -.503 & -5.984 & $.000^{* *}$ \\
& Level Education & -.023 & .038 & -.059 & -.596 & .552 \\
Lifestyle Modification & Marital Status & .082 & .042 & .162 & 1.931 & .056 \\
HPLP-II & Smoking & .040 & .049 & .108 & .824 & .412 \\
& Gender & -.039 & .051 & -.102 & -.751 & .455 \\
& Hypertension & -.018 & .036 & -.044 & -.495 & .622 \\
& Dyslipidemia & -.050 & .030 & -.132 & -1.661 & .100 \\
& DM & -.038 & .035 & -.098 & -1.078 & .284 \\
& Family History & -.038 & .030 & -.102 & -1.251 & .214 \\
& Previous Cardiac Event & -.011 & .039 & -.023 & -.288 & .774 \\
\hline
\end{tabular}

Table 4. Regression Analysis for Sociodemographic and Clinical Characteristic Factors Affecting Health Responsibility

\begin{tabular}{lllllll}
\hline Dependent Variable & Independent Variables & $\mathrm{B}$ & Std. Error & Beta & $\mathrm{t}$ & $\mathrm{P}$ Value \\
\hline & & & & & & \\
& Age & .263 & .059 & .384 & 4.469 & $.000^{* *}$ \\
& Monthly Income & .130 & .114 & .100 & 1.149 & .253 \\
& Race & -.268 & .054 & -.398 & -4.965 & $.000^{* *}$ \\
& Level Education & -.093 & .065 & -.132 & -1.423 & .158 \\
& Marital Status & .136 & .070 & .149 & 1.954 & $.054^{*}$ \\
& Smoking Status & .056 & .046 & .146 & 1.200 & .233 \\
& Gender & -.012 & .081 & -.017 & -.143 & .886 \\
& Hypertension & .000 & .064 & -.001 & -.006 & .995 \\
& Dyslipidemia & -.060 & .052 & -.088 & -1.161 & .249 \\
& DM & -.082 & .061 & -.116 & -1.343 & .182 \\
& Family History & .055 & .053 & .082 & 1.023 & .309 \\
& Previous Cardiac Event & .013 & .069 & .015 & .192 & .848 \\
\hline
\end{tabular}

Table 5. Sociodemographic and Clinical Characteristics that Affected Adherence to Physical Activity

\begin{tabular}{lllllll}
\hline Dependent Variable & Independent Variables & B & Std. Error & Beta & T & P Value \\
\hline & Age & -.285 & .058 & -.382 & -4.948 & $.000^{* *}$ \\
& Monthly Income & .225 & .111 & .158 & 2.021 & $.046^{*}$ \\
& Race & -.054 & .053 & -.074 & -1.026 & .307 \\
Physical Activity & Level education & .021 & .064 & .027 & .323 & .748 \\
& Marital Status & -.133 & .068 & -.133 & -1.948 & $.054^{*}$ \\
& Smoking Status & .043 & .045 & .102 & .936 & .352 \\
& Gender & -.259 & .080 & -.349 & -3.245 & $.002^{*}$ \\
& Hypertension & .127 & .063 & .157 & 2.014 & $.047^{*}$ \\
& Dyslipidemia & -.037 & .051 & -.049 & -.724 & .470 \\
& DM & .096 & .060 & .125 & 1.610 & .110 \\
& Family History & .037 & .052 & .051 & .713 & .477 \\
& Previous Cardiac Event & .046 & .068 & .048 & .672 & .503 \\
\hline
\end{tabular}

This study indicated that race as a factor affecting the balanced diet intake. The different culture of dietary patterns and cooking style between race in Malaysia might be contributed to this result. This reported in a study to identify the dietary pattern between different ethics in Kelantan showed Chinese adolescents showed higher score for the healthy diet intake pattern while Malay had a significantly higher score for the western-based food (Abdullah, Teo, \& Foo, 2016). Level of education was found factors significantly that affecting the balanced diet intake. This similar finding was found in a study conducted. Effective health education for patients will be increasing their awareness level, self-efficacy and improved their adherence to balanced diet intake as recommended by the healthcare workers. In the other hand, enhanced health-promoting behaviour increase the self-efficacy among patients with chronic illness such as CAD to a reduced risk of mortality and morbidity. A study found a positive relationship health-promoting behaviours and self-efficacy among patients with chronic disease (Mohamad, Mulud, Ibrahim, \& Damanhuri, (2019)

Table. 6 Independent Variables affected the adherence to balanced diet intake.

\begin{tabular}{|c|c|c|c|c|c|c|}
\hline Dependent Variable & Independent Variables & $\mathrm{B}$ & Std. Error & Beta & $\mathrm{T}$ & $P$ Value \\
\hline & Age & .081 & .050 & .145 & 1.604 & .112 \\
\hline & Monthly Income & .208 & .097 & .196 & 2.136 & $.035^{*}$ \\
\hline & Race & -.091 & .046 & -.166 & -1.972 & $.051^{*}$ \\
\hline & Level Education & -.113 & .056 & -.198 & -2.025 & $.045^{\star}$ \\
\hline & Marital Status & .158 & .060 & .213 & 2.654 & $.009^{*}$ \\
\hline & Smoking Status & .052 & .040 & .167 & 1.307 & .194 \\
\hline
\end{tabular}




\begin{tabular}{lllllll}
\hline Balanced Diet Intake & Gender & .122 & .070 & .221 & 1.755 & .082 \\
& Hypertension & -.006 & .055 & -.009 & -.102 & .919 \\
& Dyslipidemia & .001 & .044 & .002 & .022 & .983 \\
& DM & -.050 & .052 & -.088 & -.970 & .335 \\
& Family History & .012 & .046 & .022 & .259 & .796 \\
& Previous Cardiac Event & .048 & .059 & .067 & .804 & .423 \\
\hline & \multicolumn{2}{c}{$\mathrm{p}<.05,{ }^{* *} \mathrm{p}<.001$}
\end{tabular}

Table 7. Multiple Linear Regression Analysis for Sociodemographic and Clinical Characteristics on Stress Management

\begin{tabular}{lllllll}
\hline Dependent Variable & Independent Variables & B & Std. Error & Beta & t & P Value \\
\hline & Age & -.117 & .059 & -.184 & -1.986 & $.050^{*}$ \\
& Monthly Income & .019 & .113 & .016 & .168 & .867 \\
& Race & -.307 & .054 & -.492 & -5.706 & $.000^{* *}$ \\
& Level Education & -.016 & .065 & -.025 & -.249 & .804 \\
& Marital Status & .121 & .069 & .144 & 1.746 & .084 \\
Stress Management & .089 & .046 & .251 & 1.920 & .058 \\
& Smoking Status & -.091 & .081 & -.145 & -1.121 & .265 \\
& Gender & -.096 & .064 & -.140 & -1.496 & .138 \\
& Hypertension & -.059 & .051 & -.093 & -1.143 & .256 \\
& Dyslipidemia & -.041 & .061 & -.064 & -.684 & .496 \\
& DM & -.103 & .053 & -.167 & -1.938 & .055 \\
& Family History & -.056 & .069 & -.070 & -.815 & .417 \\
\hline & Previous Cardiac Event & -.059 & & & &
\end{tabular}

Table 8. Analysis for Sociodemographic and Clinical characteristics for Spiritual Growth among Patients with CAD

\begin{tabular}{lllllll}
\hline Dependent Variable & Independent variables & $\mathrm{B}$ & Std. Error & Beta & $\mathrm{t}$ & P-Value \\
\hline & Age & -.085 & .058 & -.127 & -1.464 & .146 \\
& Monthly Income & .038 & .112 & .030 & .344 & .732 \\
& Race & -.242 & .053 & -.369 & -4.567 & $.000^{* *}$ \\
& Level Education & .098 & .064 & .144 & 1.537 & .127 \\
\multirow{5}{*}{ Spiritual Growth } & Marital Status & -.052 & .069 & -.058 & -.757 & .451 \\
& Smoking Status & .026 & .046 & .070 & .568 & .572 \\
& Gender & -.201 & .080 & -.304 & -2.514 & $.014^{*}$ \\
& Hypertension & .021 & .063 & .029 & .329 & .743 \\
& Dyslipidemia & -.055 & .051 & -.083 & -1.088 & .279 \\
& DM & -.024 & .060 & -.036 & -.409 & .683 \\
& Family History & -.140 & .053 & -.215 & -2.663 & $.009^{*}$ \\
& Previous Cardiac Event & -.011 & .068 & -.013 & -.158 & .875 \\
\hline
\end{tabular}

Table 9. Analysis on Independent Variables to for Interpersonal Relationship

\begin{tabular}{|c|c|c|c|c|c|c|}
\hline Dependent Variable & Independent Variables & $B$ & Std. Error & Beta & $t$ & $P$ Value \\
\hline \multirow{12}{*}{ Interpersonal Relationship } & Age & .015 & .055 & .026 & .277 & .783 \\
\hline & Monthly Income & .210 & .106 & .191 & 1.986 & $.050^{*}$ \\
\hline & Race & -.168 & .050 & -.296 & -3.342 & $.001^{* *}$ \\
\hline & Level education & .005 & .060 & .009 & .088 & .930 \\
\hline & Marital Status & .220 & .065 & .286 & 3.395 & $.001^{* *}$ \\
\hline & Smoking Status & .025 & .043 & .078 & .578 & .565 \\
\hline & Gender & .024 & .076 & .041 & .313 & .755 \\
\hline & Hypertension & -.030 & .060 & -.049 & -.509 & .612 \\
\hline & Dyslipidemia & -.092 & .048 & -.160 & -1.917 & .058 \\
\hline & DM & -.108 & .056 & -.183 & -1.918 & .058 \\
\hline & Family History & -.039 & .050 & -.070 & -.795 & .429 \\
\hline & Previous Cardiac Event & -.052 & .064 & -.071 & -.814 & .417 \\
\hline
\end{tabular}

The spiritual growth was found significantly affected by family history and marital status affecting the interpersonal relationship. It is showing the importance of social support to improve motivation among patients with CAD to practising lifestyle modification as recommended. Lack of social support was significantly related to nonadherence explained in a study (Abate, Tareke, \& Tirfie, 2018). The stress management was affected by age, an increasing age expose the elderly to chronic disease that leads to increase the stress level. 


\subsection{Conclusion\& Recommendation}

The level of adherence to lifestyle modification is crucial among patients with CAD to reduce the risk of mortality and morbidity. The higher level of adherence to lifestyle modification is important to improve the quality of life among patients with CAD. This study suggested that factors that affect adherence to a healthy lifestyle as recommended. It is essential for healthcare workers to identify and understand the factors related to their patients that can contribute to improving the awareness, education and adherence level. The development of effective health education, health awareness and prevention can be implemented by understanding all the factors that affect the adherence level.

As an effort to improve the quality of life among patients with CAD and reduce risk of complications, cost and hospitalization, the effective health education and awareness as primary and secondary prevention must be initiated among healthcare professionals and nurses specifically. Nurses are the closest healthcare workers to the patients. The findings of the study contributed important knowledge to advance nursing care service. Results have discovered from this study have important implications for future interventions as it targeting to promoting quality of life among patients with CAD. The future researcher and healthcare workers are suggested to investigate the effectiveness of information and education provided to their patients. The relationship and impact of the impart information to their adherence on lifestyle modification.

\section{Acknowledgements}

This study fund supported by Institute of Research Management \& Innovation (IRMI), Universiti Teknologi Mara, Shah Alam, Selangor (Grant No: 600-IRMI 5/3/GIP(027/2019)).

\section{References}

Abate, T. W., Tareke, M., \& Tirfie, M. (2018). Self-care practices and associated factors among diabetes patients attending the outpatient department in Bahir Dar, Northwest Ethiopia 11 Medical and Health Sciences 1103 Clinical Sciences. BMC Research Notes.

Abdullah, N. F., Teo, P. S., \& Foo, L. H. (2016). Ethnic differences in the food intake patterns and its associated factors of adolescents in Kelantan, Malaysia. Nutrients.

Aldana, S. G., Whitmer, W. R., Greenlaw, R., Avins, A. L., Salberg, A., Barnhurst, M., ... Lipsenthal, L. (2003). Cardiovascular risk reductions associated with aggressive lifestyle modification and cardiac rehabilitation. Heart and Lung: Journal of Acute and Critical Care, 32(6), 374-382.

Alm-Roijer, C., Stagmo, M., Udén, G., \& Erhardt, L. (2004). Better knowledge improves adherence to lifestyle changes and medication in patients with coronary heart disease. European Journal of Cardiovascular Nursing, 3(4), 321-330.

Chow, C. K., Jolly, S., Rao-Melacini, P., Fox, K. A. A., Anand, S. S., \& Yusuf, S. (2010). Association of diet, exercise, and smoking modification with risk of early cardiovascular events after acute coronary syndromes. Circulation, 121(6), 750-758.

lestra, J. A. (2005). Effect Size Estimates of Lifestyle and Dietary Changes on All-Cause Mortality in Coronary Artery Disease Patients: A Systematic Review. Circulation, 112(6), 924-934.

Ministry of Health Malaysia. (2016). National Strategic Plan for Non-Communicable Disease (NSP-NCD) 2016-2025.

Mohamad, N., Mulud, Z. A., Ibrahim, M., \& Damanhuri, N. F. (2019). The Relationship between Self-Efficacy and Health Promoting Behaviour among Older Adults with Chronic Illness. Environment-Behaviour Proceedings Journal, 4(11), 73.

Mumu, S. J., Saleh, F., Ara, F., \& Ali, L. (2015). Non-Adherence to Lifestyle Modification and its Determinants among Bangladeshi type 2 Diabetic Patients. International Journal of Epidemiology, 44(suppl_1), i148-i149.

Parajuli, J., Saleh, F., Thapa, N., \& Ali, L. (2014). Factors associated with nonadherence to diet and physical activity among nepalese type 2 diabetes patients; A cross sectional study. BMC Research Notes, 7(1).

Sofi, F., Fabbri, A., Marcucci, R., Gori, A. M., Balzi, D., Barchielli, A., ... Gensini, G. F. (2011). Lifestyle modifications after acute coronary syndromes in a subset of the AMI-Florence 2 Registry. Acta Cardiologica, 66(6), 791-796.

Susan, N., Karen, R., \& Nola, J. (1995). Health Promotion Model - Instruments to Measure Health Promoting Lifestyle : Health- Promoting Lifestyle Profile [ HPLP II ] ( Adult Version ), 42-43.

Tibebu, A., Mengistu, D., \& Negesa, L. (2017). Adherence to recommended lifestyle modifications and factors associated for hypertensive patients attending chronic follow-up units of selected public hospitals in Addis Ababa, Ethiopia. Patient Preference and Adherence, 11, 323-330.

WHO. (2014). Global status report on noncommunicable diseases 2014. World Health, 176

Zeleke Negera, G., \& Charles Epiphanio, D. (2020). Prevalence and Predictors of Nonadherence to Diet and Physical Activity Recommendations among Type 2 Diabetes Patients in Southwest Ethiopia: A Cross-Sectional Study. International Journal of Endocrinology, 2020 